\title{
Large Earthquake Triggering, Clustering, and the Synchronization of Faults
}

\author{
by Christopher H. Scholz
}

\begin{abstract}
Large earthquakes are sometimes observed to trigger other large earthquakes on nearby faults. The magnitudes of the calculated Coulomb stress transfers presumed to cause the triggering are $10^{-2}-10^{-3}$ of the earthquake stress drops. The earthquake stress drops and the triggering delay times are similarly small with respect to the natural recurrence time of the earthquakes. This requires that both faults be simultaneously very close to the ends of their seismic cycles. Paleoseismological data show that for the same regions prior earthquakes have occurred in clusters of ruptures of several faults separated by long quiescent periods. Both observations suggest that synchronization is occurring between faults. Theory and observations indicate that synchronization can occur between nearby faults with positive stress coupling and intrinsic slip velocities within an entrainment threshold. In the south Iceland seismic zone, the central Nevada seismic belt, and the eastern California shear zone, several synchronous clusters that apparently act independently can be recognized. This behavior is the 3D equivalent of the phase locking that results in the seismic cycle of individual faults being dominated by large characteristic earthquakes, and for synchronization of fault segments along a given fault. Rupture patterns of repeated individual earthquakes or earthquake clusters are not identical in either the 2D or 3D cases. The state of this system, which exhibits strong indications of synchrony without exact repetition, may be called fuzzy synchrony.
\end{abstract}

\section{Introduction}

On 14 April 1928, an M 6.8 earthquake occurred in the vicinity of Plovdiv, Bulgaria, rupturing the northern bounding normal fault of an east-west striking graben for a distance of about $40 \mathrm{~km}$ along strike. Four days later an M 7.1 event ruptured the conjugate southern bounding normal fault of the same graben (Richter, 1958; Dimitrov et al., 2006; Vanneste et al., 2006). The two faults are about $20 \mathrm{~km}$ apart at the surface. Trenching of the northern (Chirpan) fault showed that it has an average recurrence time for such events of ca. 2500 yr (Vanneste et al., 2006).

Since the phenomenon was first pointed out by Das and Scholz (1981), it has become widely recognized that earthquakes often trigger earthquakes on other nearby faults. The mechanism is thought to be static or dynamic stress transfer, both of which have been well studied (for reviews, see Stein, 1999; King and Cocco, 2000; Scholz, 2002). The magnitude of such stress transfers are calculated to be typically of the order $10^{-1}-10^{-2} \mathrm{MPa}$, much smaller than the stress drop of the ensuing earthquake, typically of the order of $10 \mathrm{MPa}$ for intraplate earthquakes, which will be the examples discussed here. By any reckoning (cf. Gomberg et al., 1998), this requires that the triggered earthquake fault must have been at the extreme end of its earthquake cycle. If we were con- sidering the triggering of small earthquakes, one could argue, as is often done in the case of ordinary aftershocks or reservoir induced seismicity, that the great multitude of possible rupture points explains why there are always some spots very close to the critical point. In the case of triggered off-fault earthquakes, however, there are surprisingly many cases, as illustrated by the Bulgarian one previously described, in which a large earthquake on one fault triggers another large earthquake on one or more nearby faults. These triggered earthquakes may be of comparable or greater size than the triggering one, and their rupture zone may cover the fault over its seismogenic width and for a considerable distance along strike. This requires that both faults be simultaneously very close to the end of their respective seismic cycles. Many such cases, and the ones I will discuss here, have occurred on intraplate faults with slip rates $<1 \mathrm{~mm} / \mathrm{yr}$; because the large earthquakes that rupture them produce slip of a few meters, they have seismic cycle periods of several thousand years. The triggering delay times are typically of the order of 0.1-1 yr: this contrast with the natural recurrence time of the fault makes the same point as does the comparison of stress transfer magnitude with stress drop. Because this phenomenon is found to be fairly common, it cannot arise 
as a coincidence; there must be a mechanism whereby the seismic cycles of nearby faults become synchronized.

In the language of coupled oscillator systems, such tight synchronization is called phase locking. It is the purpose of this article to describe several case of such phase locking among faults to illustrate some of its properties and to discuss aspects of the physics behind such behavior.

\section{Several Illustrative Examples}

Several examples have been chosen that illustrate various aspects of the phase locking of faults. These are from a variety of tectonic settings: normal faulting in central Nevada, strike-slip faulting in the Mojave region of southern California, and strike-slip faulting in the south Iceland seismic zone. They all have several characteristics in common, however. They all occur within systems of evenly spaced, subparallel faults that have very similar slip rates, in these cases $0.1 \leq v \leq 1.0 \mathrm{~mm} / \mathrm{yr}$. These common characteristics, as I will show, are particularly favorable to phase locking. All of these cases are fairly well known, so I will be brief in my descriptions of them.

The most well-known example is a cluster of earthquakes that occurred in the Mojave Desert region of southern California in the 1990s. This activity occurred in the eastern California shear zone (ECSZ), a series of subparallel rightlateral strike-slip faults (Fig. 1a) with slip rates of individual faults $\sim 1 \mathrm{~mm} / \mathrm{yr}$ (Rockwell et al., 2000). Each fault system shown in Figure 1a is made up of several individually named faults or segments; Figure 1a and nomenclature follows the simplified form of Oskin et al. (2008).

This usually quiescent region was visited by a flurry of activity in the 1990s, highlighted by the M 7.3 Landers earthquake of 1992 and the M 7.1 Hector Mine earthquake of 1999, which ruptured subparallel strike-slip fault systems some $24 \mathrm{~km}$ apart (Fig. 1a). The Landers earthquake was preceded by an unusual number of moderate earthquakes (M 5.2-6.1) that have been argued to have triggered that event (King et al., 1994). It also triggered in turn the M 6.2 Big Bear earthquake, a left-lateral conjugate event, and minor seismicity on other faults of the ECSZ (Hauksson et al., 1993). This suggests there may have been a broad synchroneity of minor faults in this area, but here I will only consider the relationship between the Landers and Hector Mine earthquakes. Although the time delay between them, $7 \mathrm{yr}$, is fairly long for this phenomenon, the former is nevertheless widely believed to have triggered the latter (Parsons and Dreger, 2000; Freed and Lin, 2001). Their results showed that the triggering Coulomb stress changes were of the order 0.01 to $0.1 \mathrm{MPa}$. As mentioned before, the small value of these transferred stresses in comparison with the earthquake stress drops $\sim 10 \mathrm{MPa}$ and the long recurrence time of their faults $\sim 5000$ yrs (Rockwell et al., 2000) in comparison with the $7 \mathrm{yr}$ interval between them makes a prima facie case for phase locking of these faults. If the phase locking conjecture is correct, a spatial/temporal clustering of large earthquakes can be expected to occur
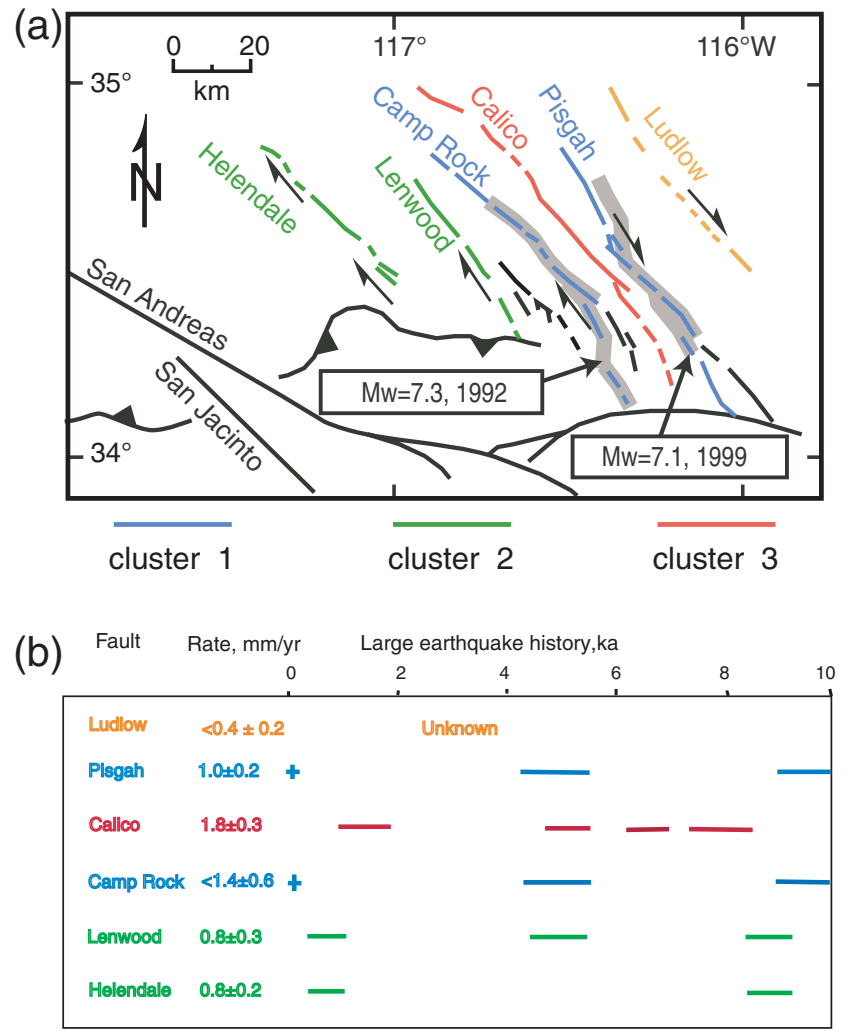

Figure 1. (a) Faults of the eastern California shear zone, Mojave region, southern California. Figure modified from Oskin et al. (2008). (b) Fault slip rates and paleoseismological histories. Data from Rockwell et al. (2000); Oskin et al. (2007, 2008); Madden et al. (2006); and Ganev et al. (2008). The faults are grouped into clusters based on their slip rates and earthquake history. There are two pairs of synchronized faults and two independent faults.

repeatedly in time. Paleoseismology studies can shed light on this problem. Although that method does not have sufficient temporal resolution to prove the phase locking hypothesis, it can show if it is plausible or not.

In a summary of paleoseismology studies of the eastern California shear zone, Rockwell et al. (2000) concluded that activity in that region was not uniform but was characterized by bursts of large earthquake activity on different faults separated by long periods of quiescence. They identified clusters of earthquakes at $0-1 \mathrm{ka}, 5-6 \mathrm{ka}, 8-9 \mathrm{ka}$, and possibly at $\sim 15 \mathrm{ka}$. The same pattern of bursts of activity on several faults interspersed with long quiescent periods has also been recognized for intraplate faults in the Los Angeles basin region (Dolan et al., 2007). Dolan et al. emphasized that the Los Angeles basin bursts are out of phase with those of the Mojave faults. This is not surprising: those two groups of faults are too far apart to be coupled through stress transfer.

This rhythmicity is a hallmark of synchrony, but is not sufficient to define it. As I will show later, to be truly synchronized, two faults must have the same slip rate. On this basis I separate the faults into clusters as shown in Figure 1b, where their slip rates and paleoseismic histories are summarized. The Camp Rock and Pisgah fault systems, which ruptured in the Landers and Hector Mine earthquakes, have slip rates 
of $\leq 1.4 \pm 0.6$ and $1.0 \pm 0.2 \mathrm{~mm} / \mathrm{yr}$ (Oskin et al., 2008). Within the uncertainties, these rates may well be identical. This fault pair has a similar rupture history, each ruptured previously at 5-6 ka and at $10 \mathrm{ka}$ (Rockwell et al., 2000; Madden et al., 2006). These data are consistent with these fault systems having remained at least partially synchronized over several seismic cycles. I call this cluster 1 . The Helendale and Lenwood faults to the northwest of cluster 1 have identical slip rates of $0.8 \pm 0.2 \mathrm{~mm} / \mathrm{yr}$, lower than those of cluster 1 . Neither of those faults participated in the recent burst of activity, but ruptured at ca. $1 \mathrm{ka}$ and again about $9 \mathrm{ka}$. These faults seem to define a different population, which I call cluster 2 . This distinction is not perfectly clean: the Lenwood fault also ruptured ca. $5 \mathrm{ka}$, suggesting that it also communicates with cluster 1 . The Calico fault system seems to behave independently of cluster 1 or cluster 2 . Although it bisects the Landers and Hector Mine ruptures, it did not participate in that sequence. This means that the Calico fault system is not synchronized with those of cluster 1 . One reason for this (another will be discussed later) is because the slip rate of the Calico fault is $1.8 \pm 0.3 \mathrm{~mm} / \mathrm{yr}$, much faster than the fault systems associated with the Landers or Hector Mine earthquakes (Oskin et al., 2007). Consistent with that, the Calico fault has ruptured four times in the last $9 \mathrm{ka}$ (Ganev et al., 2008) as compared with three events in cluster 1 and two in cluster 2 . Its most recent event was $0.6-2.0 \mathrm{ka}$, which is in the quiescent period of the other clusters. Thus, I classify the Calico fault system as a separate entity on its own: cluster 3 . Finally, the Ludlow fault, with a much lower slip rate of $0.4 \pm 0.2 \mathrm{~mm} / \mathrm{yr}$ (Oskin et al., 2008), should be unsynchronized with all the other faults in the ECSZ.

Thus, I identify two pairs of possibly synchronized faults and two unsynchronized faults, one faster and one slower than the others. The synchrony, however, is not a perfect one. The Landers and Hector Mine earthquakes were complex, involving several faults or fault segments. Although they both probably rupture repeatedly as units (Jachens et al., 2002), paleoseismological data indicate that earlier Landers earthquakes were not identical versions of the latest one (Rockwell et al., 2000).

The Basin and Range province of central and southern Nevada has been constructed by a system of subparallel, evenly spaced normal faults. A portion of the central Nevada seismic belt, the most recently active part of this system, was ruptured in a remarkable sequence of earthquakes in 1954 (Fig. 2). From July to September the Rainbow Mountain fault system (RMF), consisting of mainly east-dipping normal faults, was ruptured by a series of earthquakes (a, b, c, d, e, M 6.6, 6.4, 6.8, 5.8, and 5.5). The Fairview Peak earthquake ( $f, \mathbf{M} 7.1)$ occurred on 16 December and ruptured bilaterally on the eastward dipping Fairview fault (FF) and the Westgate and Gold King faults (WGF and GKF). The Dixie Valley earthquake ( $g$, M 6.8) occurred four minutes later and ruptured the Dixie Valley fault (DVF).

Studies of the 1954 sequence have argued that the earthquakes triggered one another (Hodgkinson et al., 1996;
Caskey and Wesnousky, 1997). As is typical in such cases, the triggering Coulomb stresses were in the range of 0.01 to $0.1 \mathrm{MPa}$, leading again to the conclusion of phase locking of these faults.

Bell et al. (2004) argued that the 1903 Wonder (M 6.5), the 1915 Pleasant Valley (M 7.6), and 1932 Cedar Mountain (M 7.2) earthquakes belong to the same cluster as the 1954 events. Although this $50 \mathrm{yr}$ period is longer than what I have been discussing up to this point, it is still very short with respect to the ca. 4-6 ka recurrence times for these faults. The ruptures in this historical sequence are highlighted on the map of Quaternary faults of the central Nevada seismic belt in Figure 3a. In their paleoseismological studies of these faults, Bell et al. found that the seismicity was clustered, with several faults rupturing within a relative short period of time in three different periods over the past 13,000 yr, each separated by long periods of quiescence. These active episodes (Fig. 3) were fairly evenly spaced in time with a recurrence period of 3-4 ka, but the fault-coupling pattern was not identical in each case. Notice that the episode of 2-4 ka (Fig. 3b) consists, in the north, of faults that did not rupture in the historical episode: this is a separate cluster. On the other hand, the episode of 6-9 ka (Fig. 3c) was close to a repeat of the historical episode. The repetition is not exact, however. For example, of the faults that participated in the 1954 sequence, the Fairview Peak fault is much slower moving than the others, with a slip rate of about $0.09 \mathrm{~mm} / \mathrm{yr}$ as opposed to $0.5 \mathrm{~mm} / \mathrm{yr}$ for the Dixie Valley fault, and had not had a prior rupture in the last $35.4 \mathrm{ka}$. Therefore, it must have participated in the 1954 sequence by coincidence. Thus, these data describe behavior that is quite similar to that of the eastern California shear zone, both of which are consistent in showing a strong synchronization signal with a large noise component. That is, there is a strong tendency to synchrony, but the patterns that repeat are not identical.

The south Iceland seismic zone (SISZ) consists of a system of north-south striking right-lateral strike-slip faults. Earthquakes, $6.0 \leq \mathbf{M} \leq 7.1$, that have occurred in the SISZ in the past $300 \mathrm{yr}$ are shown in Figure 4. Figure 4a is a space-time plot of the activity; Figure $4 \mathrm{~b}$ shows the locations of the earthquakes and their estimated rupture traces (Roth, 2004; Richwalski and Roth, 2008). It is typical in this region for large events to occur in triggered sequences. In the most recent of these, M 6.5 and 6.4 earthquakes occurred four days apart on two parallel faults separated by $14 \mathrm{~km}$ (Arnadottir et al., 2003). The sequence of 1896 consisted of five $\mathbf{M}>6$ earthquakes on different faults over an 11-day period. There were also sequences in 1784 and from 1732 to 1734. Richwalski and Roth (2008) concluded that each successive event in these sequences was triggered by the preceding events, but that the initial event in each sequence was not triggered. They also concluded that the 1912 earthquake was probably part of the 1896 sequence. Although there is no paleoseismology data for the SISZ, the fact that none of its faults have ruptured more than once in the past $300 \mathrm{yr}$ indicates that their recurrence times are $>300 \mathrm{yr}$. 


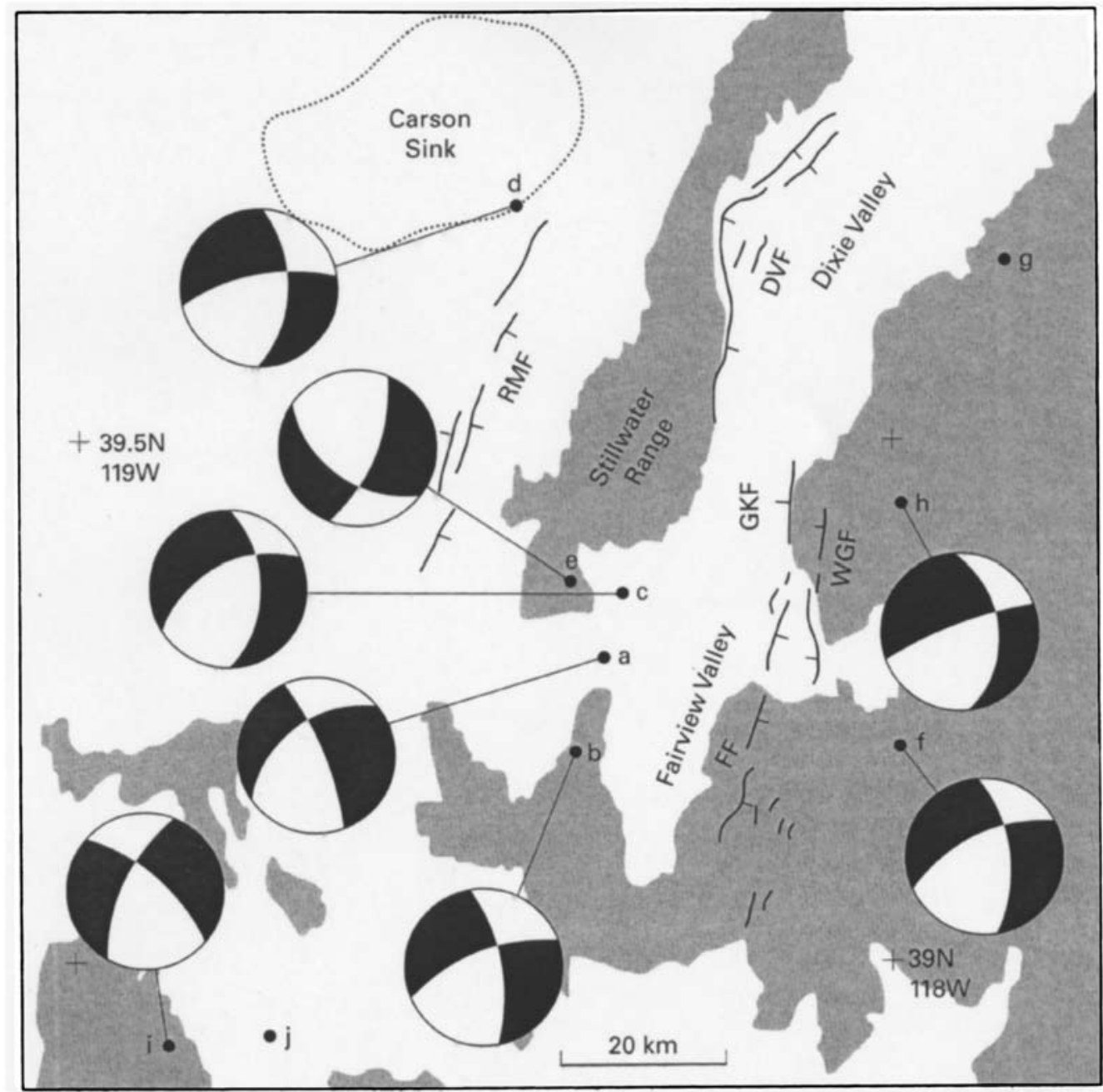

Figure 2. Earthquakes and faulting in central Nevada, 1954. Earthquakes a, b, c, d, and e (M 6.6, 6.4, 6.8, 5.8, and 5.5) occurred on the Rainbow Mountain fault (RMF) from July to September. The Fairview Peak earthquake $(f, \mathbf{M} 7.1)$ occurred on the Fairview Fault (FF) at 1107 on 16 December, followed 4 minutes later by the Dixie Valley earthquake ( $g$, M 6.8) on the Dixie Valley fault (Doser, 1986).

What is most interesting about this case is that, whereas the sychroneity of faulting is clearly evident; each synchronous cluster, 1732-1734, 1784, 1896-1912, and 2000, is distinct: none of them share a fault with another. This is the same property of the two most recent clusters in the central Nevada seismic belt described earlier. The reasons for such separate clusters will be a matter of later discussion.

In both the SISZ and the ECSZ there have been suggested fluctuations in tectonic loading rate. Seismicity in the SISZ has been suggested to have a periodicity of $\sim 140$ yrs (Stefansson and Halldorsson, 1988); this has been correlated with similar fluctuations in volcanism of the Iceland hotspot (Larsen et al., 1998). A discrepancy between the present-day geodetic rate and the geologic rate of deformation across the ECSZ led Oskin et al. (2008) to speculate that there may be variations of deformation rates there that correspond to the temporal paleoearthquake clusters of Rockwell et al. (2000). Whatever the merits of those arguments, such long period variations would not produce the synchronization that I discuss here.

\section{Synchronism and the Kuramoto Model}

Synchronization is observed in biological, chemical, physical, and social systems, and has long been a subject of study. A paradigmatic example is fireflies, which along the banks of certain rivers in Southeast Asia flash incoherently in the early evening, but before long flash in unison, creating a spectacular display. Other examples are cricket chirps, neuron firings, and coupled systems of lasers and Josephson junctions.

Suppose we consider a network of faults. A simple model of a seismically active fault is a limit cycle relaxation oscillator (cf., Scholz, 2002, pp. 294-296). Each fault evolves according to the rate at which stress accumulates on it. When a particular fault reaches a critical point, a large earthquake occurs, which reduces the stress on that fault and resets its cycle but also distributes stress onto neighboring faults. This distributed stress results in clock advances or retardations of the cycles of all the neighboring faults, their magnitude depending not only on the magnitude of the 


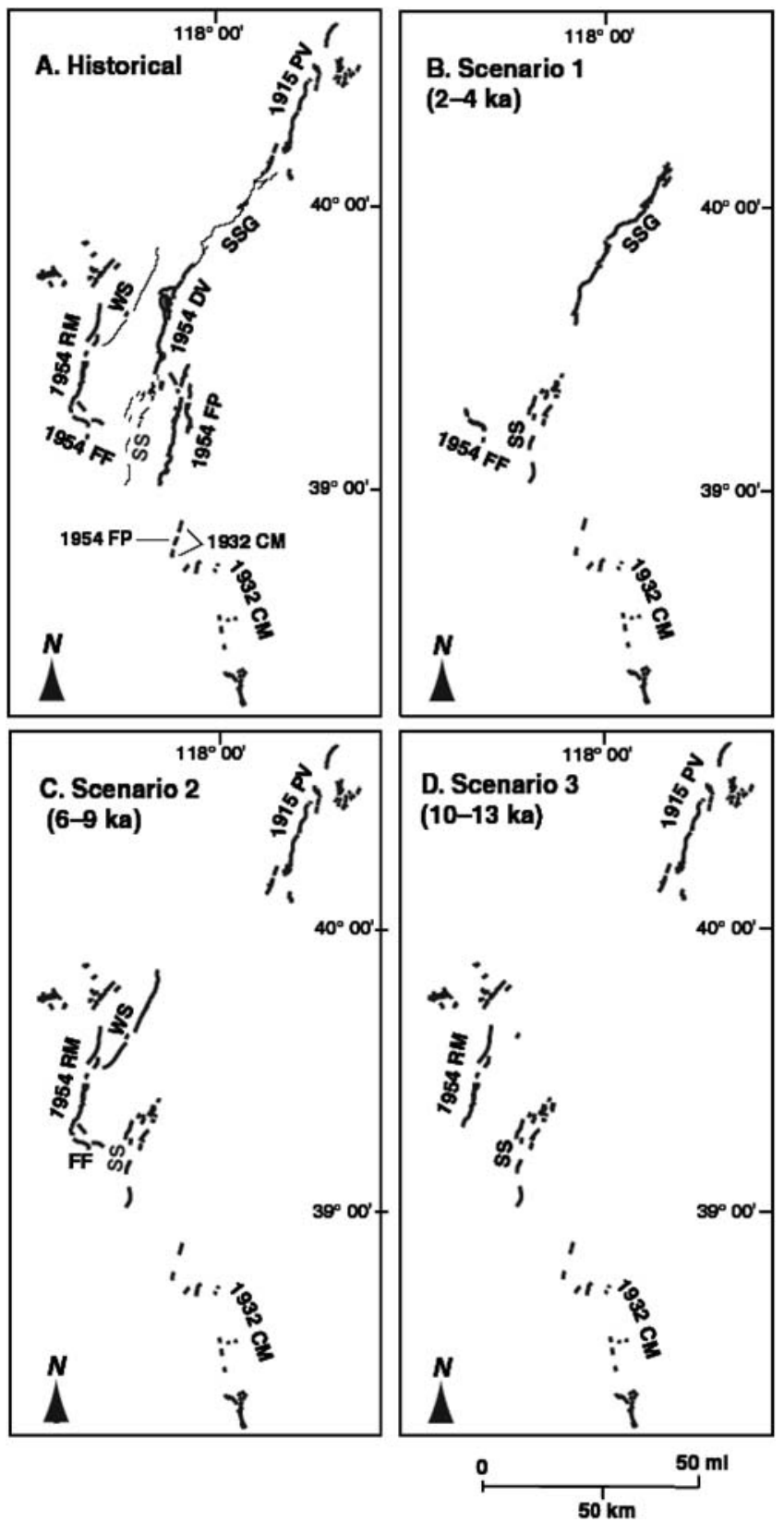

Figure 3. Summary of the paleoseismological results for major ruptures in the central Nevada seismic belt over the last 13,000 yr. The events cluster into 4 periods, as shown, with long periods of quiescence in between. Figure is from Bell et al. (2004).

transferred stress, but on the current state of the affected fault (Gomberg et al., 1998). Each stress transfer produces a phase shift either toward or away from synchrony. Imagine this occurring through many cycles. Faults that are positively coupled to one another are likely to gradually become more in phase with one another; those negatively coupled more out of phase. Those that come into phase with one another may stay that way: a condition known as phase locking.

The synchronization problem has been modeled as systems of coupled oscillators. The model of Kuramoto (1975) is the classic of the field and has spawned a large literature (for reviews, see Strogatz, 2000, 2001; Acebron et al., 2005). Kuramoto considered a system of $N$ coupled oscillators with natural frequencies $\omega_{i}$ and coupling strength $K$. He found that for $K<K_{c}$, the oscillators remain unsynchronized, but when $K>K_{c}$, after a critical number of cycles that depends on $K$, the population splits into a partially synchronized state in which those oscillators with natural frequencies close to the mean of the population become locked into synchrony while those with frequencies at the extreme tails of the distribution remain unsynchronized. The larger the value of $K$, the quicker this occurs and the broader is the phase-locked population.

These simple models of idealized populations of oscillators should not be expected to apply directly to the much noisier system of faulting and earthquakes. But consider how the basic physics imbued in those models applies to these cases.

Consider, for maximal coupling, a system of parallel equally spaced faults. The frequency of each fault-oscillator is the inverse of the recurrence time of large earthquakes that rupture it. This frequency is given by $v / \Delta u$, where $\Delta u$ is the slip in the large earthquake that ruptures the fault and $v$ is its geological slip rate of the fault. The slip $\Delta u$ is proportional to fault length, but for simplicity the faults will be considered to be of equal length so that the frequency of each fault $\omega_{i}$ is proportional to its slip rate $v_{i}$. It is customary to think that the slip rate of a fault is determined by some tectonic driver of (usually) unknown origin. The Kuramoto model shows that if the original tectonic (intrinsic) slip velocities are sufficiently close, the coupling between faults will, over time, pull them together so that they become synchronized both in frequency and phase. This is a type of self-organization of the system.

Synchronization is sensitive to the phase dependence of the coupling coefficient, $\kappa=\frac{\Delta t}{\Delta \tau}$, the ratio of clock advance to increment of stress transfer. If I consider only rate/state friction effects, this decreases with phase (time into the seismic cycle) for static stress transfer and increases with phase for dynamic stress transfer (Gomberg et al., 1998). The former would lead to desynchronization, the latter to synchronization. However, as a result of the viscoelastic coupling of the fault with the lower crust and upper mantle, fault loading is not linear in time (e.g., Johnson and Segall, 2004); this effect dominates the $r / s$ friction effect. The coupling coefficient is the inverse of the loading rate, $\kappa=\frac{1}{G \dot{\varepsilon}}$, where $\dot{\varepsilon}$ is the nearfault shear strain rate and $G$ is the shear modulus. This is plotted in Figure 5, based on the geodetic measurements of near-fault strain rates following the 1906 earthquake on the San Andreas fault from Kenner and Segall (2000). The important point is that $k$ increases continually with phase. Mirollo and Strogatz (1990) proved that any system of oscillators in which $\kappa$ increases continuously with phase will inevitably become phase locked, and once in that state, will stay in that state. For the problem under consideration, some simple models of that type have shown this result (Sammis et al., 2003). For long recurrence times, viscoelastic coupling will dominate the nonlinearity of loading in the early part of the cycle. The latter part of the cycle will be dominated by the downward 
(a)
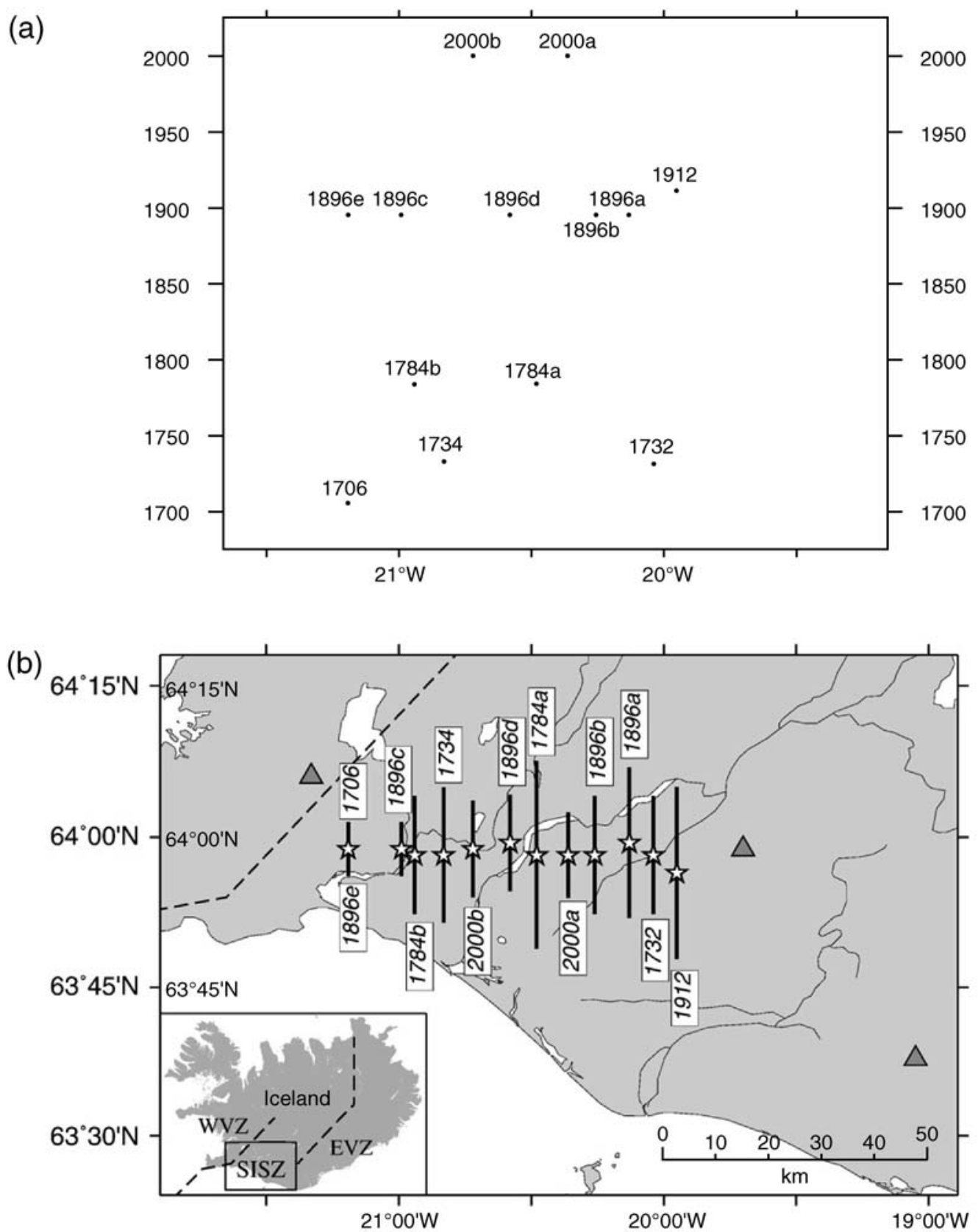

Figure 4. (a) Space-time plot of earthquakes $\mathbf{M} \geq 6$ in the south Iceland seismic zone (from Roth, 2004). (b) Map of estimated rupture traces of the same earthquakes (Richwalski and Roth, 2008).

concavity of stress-strain curves typically observed in laboratory studies, which results from accelerating stable sliding on the fault and off-fault damage as the rupture point is approached (Sammis et al., 2003).

Another feature of this form of loading is that for a given stress transfer, the clock advance is greatly increased near the end of the cycle, which increases the probability of large earthquake triggering, a point noted earlier by Chery et al. (2001) and Kenner and Simons (2005).

From the clustering observed in the ECSZ, it appears that several synchronized clusters may exist, and that relative differences in slip velocities of $20 \%$ to $30 \%$ are sufficient to prevent such synchronization. Certainly the San Andreas fault, with a slip velocity over an order of magnitude larger than the faults of the ECSZ, should be completely desynchronized from them. Even though the earthquakes in the Mojave during the 1990s transferred significant stress to the nearby sector of the San Andreas (Jaume and Sykes, 1992; Freed and Lin, 2002), this did not induce any change in seismicity there. Similarly, the M 6.7 San Fernando earthquake of 1971 produced a significant reduction of normal stress on the adjacent San Andreas fault, but this did not cause any change on it in seismicity down to the microearthquake level (Scholz, 1971). Fast moving faults may occasionally trigger 


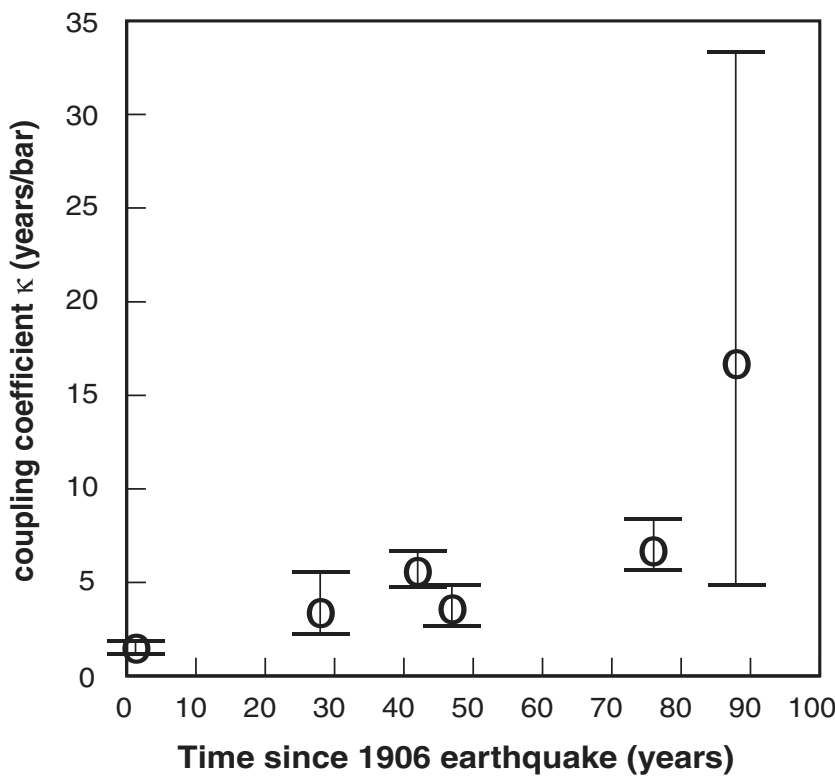

Figure 5. The coupling coefficient $\kappa=\frac{1}{G \dot{\varepsilon}}$ as a function of time after the 1906 earthquake on the San Andreas fault. The strain-rate data are from Kenner and Segall (2004).

earthquakes on slow moving faults by chance (e.g., Deng and Sykes, 1997), but the odds against the opposite happening are very high.

Kuramoto considered only the simple case in which all oscillators are globally coupled equally to each other. In a slightly more complex version, in which higher harmonics in the coupling are considered, synchronous clusters are observed (Hansel et al., 1993; Okuda, 1993). Instead of a single, central phase-locked group forming, several synchronous clusters of phase-locked groups are formed at different frequencies and out of phase with each other.

In the case of faults, coupling is local. For parallel strikeslip faults, the Coulomb stress change due to an earthquake will, except near the fault tips, be dominated by the change in the fault parallel component of shear stress. For simplicity, let us take this as the coupling function. In Figure 6 this is shown as a function of perpendicular distance along the center line from strike-slip faults of various length to width ratios where its magnitude is normalized by the earthquake stressdrop and distance by fault width $W$ (Kostrov and Das, 1984). For long faults the stress change is negative at distances $<$ $0.8 \mathrm{~W}$ and positive at greater distances, gradually dying out from a maximum at about $1.4 \mathrm{~W}$. In the south Iceland seismic zone, $W \sim 10 \mathrm{~km}$ (Stefansson et al., 1993; Pedersen et al., 2003) and the fault spacing is $5 \mathrm{~km}$ (Fig. 4). Therefore, nearest neighbor faults will be negatively coupled and positive coupling will occur only with more distant faults. The nearest distance between triggered faults for all the triggering sequences of Figure 4 is in all but one case greater than $10 \mathrm{~km}$, with a mean value of $21 \mathrm{~km}$; the exception is $1896 \mathrm{~b}$, but the felt reports for that event are also consistent with it occurring on a northern extent of the 1896a fault rupture (Einarsson et al., 1981). The negative coupling between

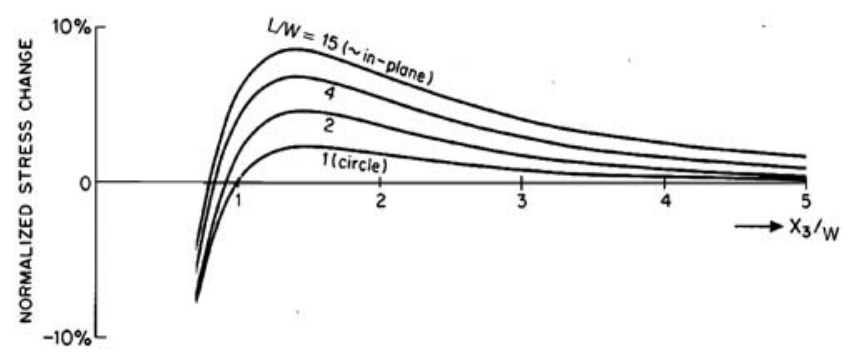

Figure 6. The coseismic change in the fault parallel component of shear stress shown as a function of normalized distance from strike-slip faults of several aspect ratios. The stress change is normalized by the earthquake stress drop, the distance by the fault width (Kostrov and Das, 1984).

nearest neighbor faults results in the system breaking into synchronous clusters in which nearest neighbors do not belong to any one cluster. These synchronous clusters do not interact with one another (Richwalski and Roth, 2008), at least on the timescale of Figure 4. In the ECSZ, the spacing between the Calico fault and the Camp Rock and Pisgah systems on either side is $12 \mathrm{~km}$. The fault width there is $15 \mathrm{~km}$ (Meade and Hager, 2005), so the Calico fault is just at the neutral point: it just avoids the stress shadow of its neighboring faults, which is probably why the faults form at this spacing (see, e.g., Hu and Evans, 1989). Freed and Lin (2002) showed that a model with a bulk viscous lower crust would predict that postseismic relaxation from Landers would load the Calico fault, but a more realistic model in which postseismic relaxation occurs by deep afterslip (Savage and Svarc, 1997) has the same result as $W$ increasing with time, which would progressively cast the stress shadows of Landers and Hector Mine over the Calico fault. This would provide a second reason why the Calico fault is not synchronized with either of its nearest neighbors.

\section{Discussion and Conclusions}

The common occurrence of triggering of a large earthquake by other large earthquakes on nearby faults and the observation of space-time clustering of large earthquakes in the paleoseismic record are both indicators of sychronization occurring between faults. All the cases reviewed here involve subparallel groups of faults moving at similar slip rates. These are particularly favored situations because parallel faults have high stress coupling along their entire lengths, and because in order to become entrained into synchrony, the intrinsic slip rate of the faults have to be similar (within 20\% to 30\%, according to the results from the ECSZ). This is not the only situation in which synchronization can occur, however. Abutting conjugate faults also provide strong coupling and exhibit triggered large earthquakes. Examples are the $\mathbf{M}$ 6.6 Superstition Hills and $\mathbf{M}$ 6.2 Elmore Ranch, California, earthquakes of 1987 (Hudnut et al., 1989) and the two M 7 Gazli, Uzbekistan, earthquakes of 1976 (Kristy et al., 1980; Amorese and Grasso, 1996). 
The south Iceland seismic zone demonstrates the formation of synchronous clusters. In that case the primary driver for the formation of separate clusters is the negative coupling between nearest neighbor faults. The formation of separate clusters in the eastern California shear zone, on the other hand, appears to result, in addition, from the variation of slip rates among the faults, of which only those within the entrainment range of each other can become synchronized.

The $2 \mathrm{D}$ equivalent of this synchrony is the phase locking among elements of an individual fault that results in the large characteristic earthquakes that define the seismic cycle (Brown et al., 1991; Herz and Hopfield, 1995). Synchrony is also observed between segments of a given fault. A wellknown example is the sequence of six $\mathbf{M}>7$ earthquakes that, progressing from east to west, ruptured $\sim 1000 \mathrm{~km}$ of the North Anatolian fault from 1939 to 1967. These earthquakes have been argued to have sequentially triggered one another (Stein et al., 1997) so they must have been in synchrony; the 1943 earthquake was not triggered (Scholz, 2002 , p. 234), so it occurred naturally in synchrony. The paleoseismic record indicates that such sequences have occurred every few hundred years on the North Anatolian fault (Hartleb et al., 2006). This space-time clustering in 2D is very similar to the 3D clustering described earlier. The shorter recurrence times reflect the greater slip velocity, $\sim 24 \mathrm{~mm} / \mathrm{yr}$ (Reilinger et al., 2006) of the North Anatolian fault compared with the other cases discussed.

Synchrony in three dimensions, phase locking of faults, is rarer and more muted because the coupling is weaker and because of the additional requirement that the intrinsic slip velocities of the faults be within an entrainment threshold for synchronization to occur.

Paleoseismological and historical earthquake data, though crude and often incomplete, nevertheless show that in both the $2 \mathrm{D}$ and $3 \mathrm{D}$ cases there is no exact repetition of individual ruptures or clusters of ruptures. This is not surprising considering the complexity of fault systems. Nonetheless, the signature of synchrony is clearly evident. The state of this system may be called fuzzy synchrony.

\section{Data and Resources}

All data are taken from the cited references.

\section{Acknowledgments}

I thank Leonardo Seeber and Bruce Shaw for helpful discussions and James Dolan and Tom Rockwell for explaining to me the paleoseismological data for the eastern California shear zone.

\section{References}

Acebron, J. A., L. L. Bonilla, C. J. P. Vicente, F. Ritort, and R. Spigler (2005). The Kuramoto model: A simple paradigm for synchronization phenomena, Rev. Mod. Phys. 77, no. 1, 137-185.

Amorese, D., and J. R. Grasso (1996). Rupture planes of the Gazli earthquakes deduced from local stress tensor calculation and geodetic data inversion: Geotectonic implications, J. Geophys. Res. B Solid Earth Planets 101, no. B5, 11,263-11,274.

Arnadottir, T., S. Jonsson, R. Pedersen, and G. B. Gudmundsson (2003). Coulomb stress changes in the South Iceland seismic zone due to two large earthquakes in June 2000, Geophys. Res. Lett. 30, no. 5 .

Bell, J. W., S. J. Caskey, A. R. Ramelli, and L. Guerrieri (2004). Pattern and rates of faulting in the central Nevada seismic belt, and paleoseismic evidence for prior beltlike behavior, Bull. Seismol. Soc. Am. 94, no. 4, $1229-1254$.

Brown, S. R., C. H. Scholz, and J. B. Rundle (1991). A simplified springblock model of earthquakes, Geophys. Res. Lett. 18, no. 2, 18,21518,218 .

Caskey, S. J., and S. G. Wesnousky (1997). Static stress changes and earthquake triggering during the 1954 Fairview Peak and Dixie Valley earthquakes, central Nevada, Bull. Seismol. Soc. Am. 87, no. 3, 521-527.

Chery, J., S. Merkel, and S. Bouissou (2001). A physical basis for time clustering of large earthquakes, Bull. Seismol. Soc. Am. 91, no. 6, $1685-1693$

Das, S., and C. H. Scholz (1981). Off-fault aftershock clusters caused by shear stress increase?, Bull Seismol. Soc. Am. 71, 1669-1675.

Deng, J. S., and L. R. Sykes (1997). Evolution of the stress field in Southern California and triggering of moderate-size earthquakes: A 200-year perspective, J. Geophys. Res. B Solid Earth Planets 102, no. B5, 9859-9886.

Dimitrov, D., T. Camelbeeck, J. C. Ruegg, I. Georgiev, and E. Botev (2006). Surface seismic deformations in the Plovdiv region (Bulgaria) by space geodesy and seismological data, in SENS 2006: Second Scientific Conference with International Participation, Varna, Bulgaria.

Dolan, J. F., D. D. Bowman, and C. G. Sammis (2007). Long-range and long-term fault interactions in Southern California, Geology 35, no. $9,855-858$.

Doser, D. I. (1986). Earthquake processes in the Rainbow MountainFairview Peak-Dixie Valley, Nevada, region 1954-1959, J. Geophys. Res. 91, 12,572-12,586.

Einarsson, P., S. Bjornsson, G. Foulger, R. Stefansson, and T. Skaftadottir (1981). Seismicity pattern in the South Iceland seismic zone, in Earthquake Prediction, an International Review, D. W. Simpson and P. G. Richards (Editors), American Geophysical Union, Maurice Ewing Ser. 4, Washington, D.C., 141-152.

Freed, A. M., and J. Lin (2001). Delayed triggering of the 1999 Hector Mine earthquake by viscoelastic stress transfer, Nature 411, 180-183.

Freed, A. M., and J. Lin (2002). Accelerated stress buildup on the southern San Andreas fault and surrounding regions caused by Mojave Desert earthquakes, Geology 30, no. 6, 571-574.

Ganev, P. N., J. F. Dolan, M. Oskin, K. Le, and L. A. Owen (2008). Paleoseismologic evidence for multiple Holocene earthquakes on the Calico fault: Implications for earthquake clustering in the eastern California shear zone, SCEC Annual Meeting Proceedings and Abstracts, XVIII, 158-159.

Gomberg, J., N. M. Beeler, M. L. Blanpied, and P. Bodin (1998). Earthquake triggering by transient and static deformations, J. Geophys. Res. $B$ Solid Earth Planets 103, no. B10, 24,411-24,426.

Hansel, D., G. Mato, and C. Meunier (1993). Clustering and slow switching in globally coupled phase oscillators, Physical Review E 48, no. 5, 3470-3477.

Hartleb, R. D., J. F. Dolan, O. Kozaci, H. S. Akyuz, and G. G. Seitz (2006). A 2500-yr-long paleoseismologic record of large, infrequent earthquakes on the North Anatolian fault at Cukurcimen, Turkey, Geol. Soc. Am. Bull. 118, no. 7-8, 823-840.

Hauksson, E., L. M. Jones, K. Hutton, and D. Eberhart-Phillips (1993). The 1992 Landers earthquake sequence-Seismological observations, J. Geophys. Res. B Solid Earth Planets 98, no. B11, 19,835-19,858.

Herz, A. V. M., and J. J. Hopfield (1995). Earthquake cycles and neural reverberations-Collective oscillations in systems with pulse-coupled threshold elements, Phys. Rev. Lett. 75, no. 6, 1222-1225. 
Hodgkinson, K. M., R. S. Stein, and G. C. P. King (1996). The 1954 rainbow Mountain-Fairview Peak-Dixie Valley earthquakes: A triggered normal faulting sequence, J. Geophys. Res. B Solid Earth Planets 101, no. B11, 25,459-25,471.

Hu, M. S., and A. G. Evans (1989). The cracking and decohesion of thin-films on ductile substrates, Acta Metall. 37, no. 3, 917-925.

Hudnut, K., L. Seeber, and J. Pacheco (1989). Cross-fault triggering in the November 1987 Superstition Hills earthquake sequence, Southern California, J. Geophys. Res. Lett. 16, 199-202.

Jachens, R. C., V. E. Langenheim, and J. C. Matti (2002). Relationship of the 1999 Hector Mine and 1992 Landers fault ruptures to offsets on neogene faults and distribution of late Cenozoic basins in the eastern California shear zone, Bull. Seismol. Soc. Am. 92, no. 4, $1592-1605$.

Jaume, S. C., and L. R. Sykes (1992). Changes in state of stress on the southern San Andreas fault resulting from the California earthquake sequence of April to June 1992, Science 258, no. 5086, 1325-1328.

Johnson, K. M., and P. Segall (2004). Viscoelastic earthquake cycle models with deep stress-driven creep along the San Andreas fault system, J. Geophys. Res. B Solid Earth Planets 109, no. B10.

Kenner, S. J., and P. Segall (2000). Postseismic deformation following the 1906 San Francisco earthquake, J. Geophys. Res. 105, 13,195-13,209.

Kenner, S. J., and M. Simons (2005). Temporal clustering of major earthquakes along individual faults due to post-seismic reloading, Geophys. J. Int. 160, no. 1, 179-194.

King, G. C. P., and M. Cocco (2000). Fault interaction by elastic stress changes: New clues from earthquake sequences, Adv. Geophys. 44, $1-38$.

King, G. C. P., R. S. Stein, and J. Lin (1994). Static stress changes and the triggering of earthquakes, Bull. Seismol. Soc. Am. 84, no. 3, 935-953.

Kostrov, B. V., and S. Das (1984). Evaluation of stress and displacementfields due to an elliptical plane shear crack, Geophysical J. R. Astr. Soc. 78, no. 1, 19-33.

Kristy, M., L. Burdick, and D. Simpson (1980). The focal mechanisms of the Gazli, USSR, earthquakes, Bull. Seismol. Soc. Am. 70, 1737-1750.

Kuramoto, Y. (1975). Lecture Notes in Physics No. 30, in International Symposium on Mathematical Problems in Theoretical Physics, H. Araki (Editor), Springer, New York, 420.

Larsen, G., M. T. Gudmundsson, and H. Bjornsson (1998). Eight centuries of periodic volcanism at the center of the Iceland hotspot revealed by glacier tephrostratigraphy, Geology 26, no. 10, 943-946.

Madden, C. L., C. M. Rubin, and A. Streig (2006). Holocene and latest Pleistocene activity on the Mesquite Lake fault near Twenty-nine Palms, eastern California shear zone: Implications for fault interaction, Bull. Seismol. Soc. Am. 96, no. 4, 1305-1320.

Meade, B. J., and B. H. Hager (2005). Block models of crustal motion in Southern California constrained by GPS measurements, J. Geophys. Res. 110, B3, doi 10.1029/2004JB003209.

Mirollo, R. E., and S. H. Strogatz (1990). Synchronization of pulse-coupled biological oscillators, SIAM J. Appl. Math. 50, no. 6, 1645-1662.

Okuda, K. (1993). Variety and generality of clustering in globally coupled oscillators, Phys. Nonlinear Phenom. 63, no. 3-4, 424-436.

Oskin, M., L. Perg, D. Blumentritt, S. Mukhopadhyay, and A. Iriondo (2007). Slip rate of the Calico fault: Implications for geologic versus geodetic rate discrepancy in the eastern California shear zone, J. Geophys. Res. B Solid Earth Planets 112, no. 3.

Oskin, M., L. Perg, E. Shelef, M. Strane, E. Gurney, B. Singer, and X. Zhang (2008). Elevated shear zone loading rate during an earthquake cluster in eastern California, Geology 36, no. 6, 507-510.

Parsons, T., and D. S. Dreger (2000). Static-stress impact of the 1992 Landers earthquake sequence on nucleation and slip at the site of the $1999 M=7.1$ Hector Mine earthquake, Southern California, Geophys. Res. Lett. 27, 1949-1952.

Pedersen, R., S. Jonsson, T. Arnadottir, F. Sigmundsson, and K. L. Feigl (2003). Fault slip distribution of two June $2000 M_{\mathrm{w}} 6.5$ earthquakes in South Iceland estimated from joint inversion of InSAR and GPS measurements, Earth Planet. Sci. Lett. 213, no. 3-4, 487-502.

Reilinger, R., S. McClusky, P. Vernant, S. Lawrence, S. Ergintav, R. Cakmak, H. Ozener, F. Kadirov, I. Guliev, R. Stepanyan, M. Nadariya, G. Hahubia, S. Mahmoud, K. Sakr, A. ArRajehi, D. Paradissis, A. Al-Aydrus, M. Prilepin, T. Guseva, E. Evren, A. Dmitrotsa, S. V. Filikov, F. Gomez, R. Al-Ghazzi, and G. Karam (2006). GPS constraints on continental deformation in the Africa-Arabia-Eurasia continental collision zone and implications for the dynamics of plate interactions, J. Geophys. Res. B Solid Earth Planets 111, no. B5.

Richter, C. F. (1958). Elementary Seismology W. H. Freeman, San Francisco.

Richwalski, S. M., and F. Roth (2008). Elastic and viscoelastic stress triggering in the South Iceland seismic zone due to large earthquakes since 1706, Tectonophysics 447, 127-135.

Rockwell, T. K., S. Lindvall, M. Herzberg, D. Murbach, T. Dawson, and G. Berger (2000). Paleoseismology of the Johnson Valley, Kickapoo, and Homestead Valley faults: Clustering of earthquakes in the eastern California shear zone, Bull. Seismol. Soc. Am. 90, no. 5, 1200-1236.

Roth, F. (2004). Stress changes modelled for the sequence of strong earthquakes in the South Iceland seismic zone since 1706, Pure Appl. Geophys. 161, no. 7, 1305-1327.

Sammis, C. G., J. F. Dolan, and S. W. Smith (2003). Phase-locking in coupled non-linear oscillators: and explanation for observed temporal and spatial correlations and anti-correlation of large earthquakes (abstract), EOS Trans. AGU 84, no. F787.

Savage, J. C., and J. L. Svarc (1997). Postseismic deformation associated with the $1992 M_{\omega}=7.3$ Landers earthquake, Southern California, J. Geophys. Res. B Solid Earth Planets 102, no. B4, 7565-7577.

Scholz, C. H. (1971). Microearthquakes on the San Andreas fault and aftershocks of the San Fernando earthquake, in The San Fernando, California, Earthquake of February 9, U.S. Geol. Surv. Profess. Pap. 733, Washington, D.C., 33-37.

Scholz, C. H. (2002). The Mechanics of Earthquakes and Faulting, Cambridge University Press, Cambridge.

Stefansson, R., and P. Halldorsson (1988). Strain release and strain buildup in the South Iceland seismic zone, Tectonophysics 152, no. 3-4, 267-276.

Stefansson, R., R. Bodvarsson, R. Slunga, P. Einarsson, S. Jakobsdottir, H. Bungum, S. Gregersen, J. Havskov, J. Hjelme, and H. Korhonen (1993). Earthquake prediction research in the South Iceland seismic zone and the Sil Project, Bull. Seismol. Soc. Am. 83, no. 3, 696-716.

Stein, R. S. (1999). The role of stress transfer in earthquake occurrence, Nature 402, no. 6762, 605-609.

Stein, R. S., A. A. Barka, and J. H. Dieterich (1997). Progressive failure on the North Anatolian fault since 1939 by earthquake stress triggering, Geophys. J. Int. 128, no. 3, 594-604.

Strogatz, S. H. (2000). From Kuramoto to Crawford: Exploring the onset of synchronization in populations of coupled oscillators, Phys. Nonlinear Phenom. 143, no. 1-4, 1-20.

Strogatz, S. H. (2001). Exploring complex networks, Nature 410, no. 6825, 268-276.

Vanneste, K., A. Radulov, P. De Martini, G. Nikolov, T. Petermans, K. Verbeeck, T. Camelbeeck, D. Pantosti, D. Dimitrov, and S. Shanov (2006). Paleoseismologic investigation of the fault rupture of the 14 April 1928 Chirpan earthquake ( $M$ 6.8), southern Bulgaria, J. Geophys. Res. B Solid Earth Planets 111, no. 1.

Lamont-Doherty Earth Observatory

Columbia University

Palisades, New York 10964

scholz@1deo.columbia.edu

Manuscript received 22 September 2009 